\title{
Reliabilty and Cost Benefit Analysis of DG Integrated Distribution System
}

\author{
Ch. V. S. S. Sailaja ${ }^{* 1}$, P. V. N. Prasad ${ }^{2}$ \\ ${ }^{1}$ Department of Electrical and Electronics Engineering, Vasavi College of Engineering, Hyderabad, India \\ ${ }^{2}$ Department of Electrical Engineering, University College of Engineering, Osmania University, \\ Hyderabad, India \\ Corresponding author, e-mail: sailajacvss@gmail.com ${ }^{1}$, pvnprasad09@gmail.com²
}

\begin{abstract}
Integration of Distributed generation (DG) results in a number of advantages ranging from reduction in losses to delayed generation and transmission capacities. In this paper the impact of DGs on reliability is considered and their effect on reliability in terms of number and location is evaluated. The integration of DG changes configuration of the radial system. This point is considered for evaluating the load point indices. The cost effectiveness of number of DGs is evaluated for determining the returns on the $D G$ investment cost. The above analysis is carried out on a RBTS Bus 2 system. The reliability indices are calculated using FMEA technique.
\end{abstract}

Keywords: distributed generation, RBTS bus 2, fmea technique, cost worth analysis

\section{Introduction}

The reliability of the distribution system is becoming a major concern in the changing scenario of socio and economic conditions of the consumers. Utilities are adopting different procedures like, changing the existing system form overhead to underground cable, providing backup devices and reconfiguring the system to improve the reliability of the system. The reliability of the system can also be improved by adopting reliability centered maintenance, implementing automation, adopting smart grid technologies and supporting the DG technologies. These methodologies and their effect on the system reliabilities were studied by several researchers. The improvement in the reliability when an existing overhead line system is changed to underground cable system is presented by Guldbrand [1]. Lina bertling et al., proposed that the reliability centered maintenance can considerably effect the reliability of the system [2, 3]. Cho [4] and Zhu [5] discussed the effect of reconfiguration of the distribution system. Automation of the system also can improve the system reliability by reducing the outage duration significantly. This is discussed by Heidari [6] and the improvement of reliability is evaluated by providing automation to the system. The improvement in the reliability can be obtained by implementing the smart grid technologies into the system and their effect is evaluated in [7]. Providing DG at the customer location can also improve the reliability of the system considerably. Seyed ali et al [8] have studied the effect of DG on distribution system reliability by considering the misoperation of fuse and recloser. Yue Yuan [9] has considered the effect of DG location on the distribution system reliability. Atthapol et al have evaluated the effect of size and location of DG on distribution system reliability and also calculated the cost of interruption [10]. In the earlier works on reliability assessment of integrating DG into the system, many authors have considered mostly single DG connected to the system. In the reliability evaluation process the change in the system configuration from radial to mesh was ignored. In the cost benefit analysis only interruption cost is considered and the capital cost of the DGs was not considered. This paper attempts to evaluate the effect of multiple DGs on the system reliability. In the reliability evaluation the change in the radial configuration of the system is taken into account. The number of DGs that can be integrated is determined based on the cost worth analysis considering the capital cost. The effect of DG and the methodology involved in the reliability analysis is discussed in section 2 and the test system and assumptions are presented in section 3 . The detailed reliability evaluation procedure and cost worth analysis are presented in section 4 and the conclusions are given in section 5 . 


\section{Distributed Generation and Reliability}

\subsection{Distribution System Reliability}

The objective of the distribution system is to provide the uninterrupted power to the customer. The reliability indices of the power system is measured in terms number of interruption, duration of interruption and the total energy lost during the interruptions. These indices are defined in the following.

\section{SAIFI (System Average Interruption Frequency Index)}

$$
\text { SAIFI }=\frac{\text { total number of customer interruptions }}{\text { total number of customers served }}=\frac{\sum \lambda_{\mathrm{i}} \mathrm{N}_{\mathrm{i}}}{\sum \mathrm{N}_{\mathrm{i}}}
$$

CAIFI (Customer Average Interruption Frequency Index)

$$
\text { CAIFI }=\frac{\text { total number of customer interruptions }}{\text { total number of customers affected }}=\frac{\sum \lambda_{i} N_{i}}{\sum N_{c}}
$$

and is measured in average interruptions per customer interrupted

SAIDI (System Average Interruption Duration Index)

$$
\text { SAIDI }=\frac{\text { sum of customer interruption durations }}{\text { total number of customers served }}=\frac{\sum \mathrm{U}_{\mathrm{i}} \mathrm{N}_{\mathrm{i}}}{\sum \mathrm{N}_{\mathrm{i}}}
$$

It is measured in hours/customer

CAIDI (Customer Average Interruption Duration Index)

$$
\text { CAIDI }=\frac{\text { sum of customer interruption durations }}{\text { total number of customer interrruptions }}=\frac{\sum \mathrm{U}_{\mathrm{i}} \mathrm{N}_{\mathrm{i}}}{\sum \lambda_{\mathrm{i}} \mathrm{N}_{\mathrm{i}}}
$$

It is measured in hours/customer interruption

ASAI (Average Service Availability Index)

$$
\text { ASAI }=\frac{\text { customer hours of available service }}{\text { customer hours demanded }}=\frac{\sum N_{i} * 8760-\sum U_{i} N_{i}}{\sum N_{i} * 8760}
$$

ENS (Energy Not Supplied by the system)

$$
\mathrm{ENS}=\sum L_{a i} * U_{i} \mathrm{MWh} / \text { year }
$$

AENS (Average Energy not supplied)

$$
\text { AENS }=\frac{\text { total energy not supplied }}{\text { customer hours detotal number of customers served }}=\frac{\sum L_{a i} * U_{i}}{\sum N_{i}}
$$

AENS is measured in $\mathrm{kWh} /$ customer year

Where $\lambda_{i}$ is the failure rate, $U_{i}$ is the annual outage time, $L_{a i}$ is the average load connected to load point $\mathrm{i}$ and $\mathrm{N}_{\mathrm{i}}$ is the number of customers of load point $\mathrm{i}$.

The reliability of the system is evaluated using FMEA technique. In this method the failure modes of the load points are determined to evaluate the load point indices.

\subsection{DG Impact on Distribution System Relibility}

Distribution generation refers to power generation at the point of consumption. Generating power on site rather than centrally eliminates the cost, complexity, interdependencies and inefficiencies associated with transmission and distribution. Consumers are using the distributed generation mainly to meet their load demands in the event of grid disturbances. Generally DG technologies are based on renewable energy sources and DGs that can be installed to meet the total load or a percentage of the total load. In the event of excess 
generation from DG the power can be exported to the grid. Thus installation of DG results in change of power flow in the network. Therefore whenever a DG is connected to the system the system radial configuration changes to mesh configuration and the reliability analysis of DG connected systems follows the reliability analysis for parallel systems. The failure rate and outage time of load points are calculated using the below equations.

$$
\begin{aligned}
& \lambda_{L P}=\sum_{i=0}^{N U} \sum_{j=0}^{N D} \lambda_{u i} \lambda_{d i}\left(r_{u i}+r_{d i}\right) \\
& U_{L P}=\sum_{i=0}^{N U} \sum_{j=0}^{N D} \lambda_{u i} \lambda_{d i} r_{u i} r_{d j}
\end{aligned}
$$

Where $\lambda_{L P}$ is the failure rate of the load point, $\lambda_{u i}$ is the failure rate of the DG upstream section, $\lambda_{d i}$ is the failure rate of the DG down stream sections, $\lambda_{K}$ is the failure rate of the section $\mathrm{K}, \mathrm{r}_{\mathrm{ui}}$ is the repair time of the DG upstream sections, $r_{d i}$ is the repair time of the DG downstream sections. $U_{L P}$ is the outage time of the load point. $U_{K}$ is the outage time of the section $\mathrm{K}$. For each load point failures on the associated section result in load point outage no matter whether DG exists or not. Therefore the failure rate and outage time of the section is added to equation 1 and 2. In addition, for the load points located on the downstream section of the DG, the load is also curtailed if a fault occurs on a section between load point and DG. The modified equations for the upstream section and downstream section of $D G$ are given in the following equations. For upstream sections

$$
\begin{aligned}
& \lambda_{L P}^{*}=\lambda_{L P}+\lambda_{K} \\
& U_{L P}^{*}=U_{L P}+U_{K}
\end{aligned}
$$

For downstream sections

$$
\begin{aligned}
& \lambda_{L P}^{*}=\lambda_{L P}+\lambda_{K}+\sum_{i=1}^{N D} \lambda_{D K i} \\
& U_{L P}^{*}=U_{L P}+U_{K}+\sum_{i=1}^{N D} U_{D K i} \\
& r_{L P}^{*}=\frac{\lambda_{L P}^{*}}{U_{L P}^{*}}
\end{aligned}
$$

If $P_{D G}$ is the probability of $D G$ supplying the load in the event of contingency, then the load point indices are evaluated as

$$
\begin{aligned}
& \lambda=P_{D G} \lambda_{L P}^{*}+\left(1-P_{D G}\right) \lambda_{L P} \\
& r=P_{D G} r_{L P}^{*}+\left(1-P_{D G}\right) r_{L P}
\end{aligned}
$$

\section{Reliability Evaluation of the Test System}

The impact of connecting DG on the system is evaluated considering the RBTS bus 2 [11] and is shown in Figure 1. This bus has 4 feeders and 22 load points consisting of different types of customers. The following are the assumptions for the present case study.

a. Failures on the incoming $33 \mathrm{kV}$ supply circuits are ignored.

b. The faults on $33 \mathrm{kV}$ bus are ignored.

c. The $11 \mathrm{kV}$ breakers operate successfully when required

d. Disconnects in the main feeder sections and fuses in the laterals and they operate with $100 \%$ efficiency whenever a fault occurs.

e. The DG connected is capable of taking the load on the feeder when operating under islanding mode

f. The DG operates with $100 \%$ reliability in the event of contingency

g. The DG start up time is negligible.

h. The DGs connected in the system do not violate the existing system condition such as voltage profile / protection co-ordination. 


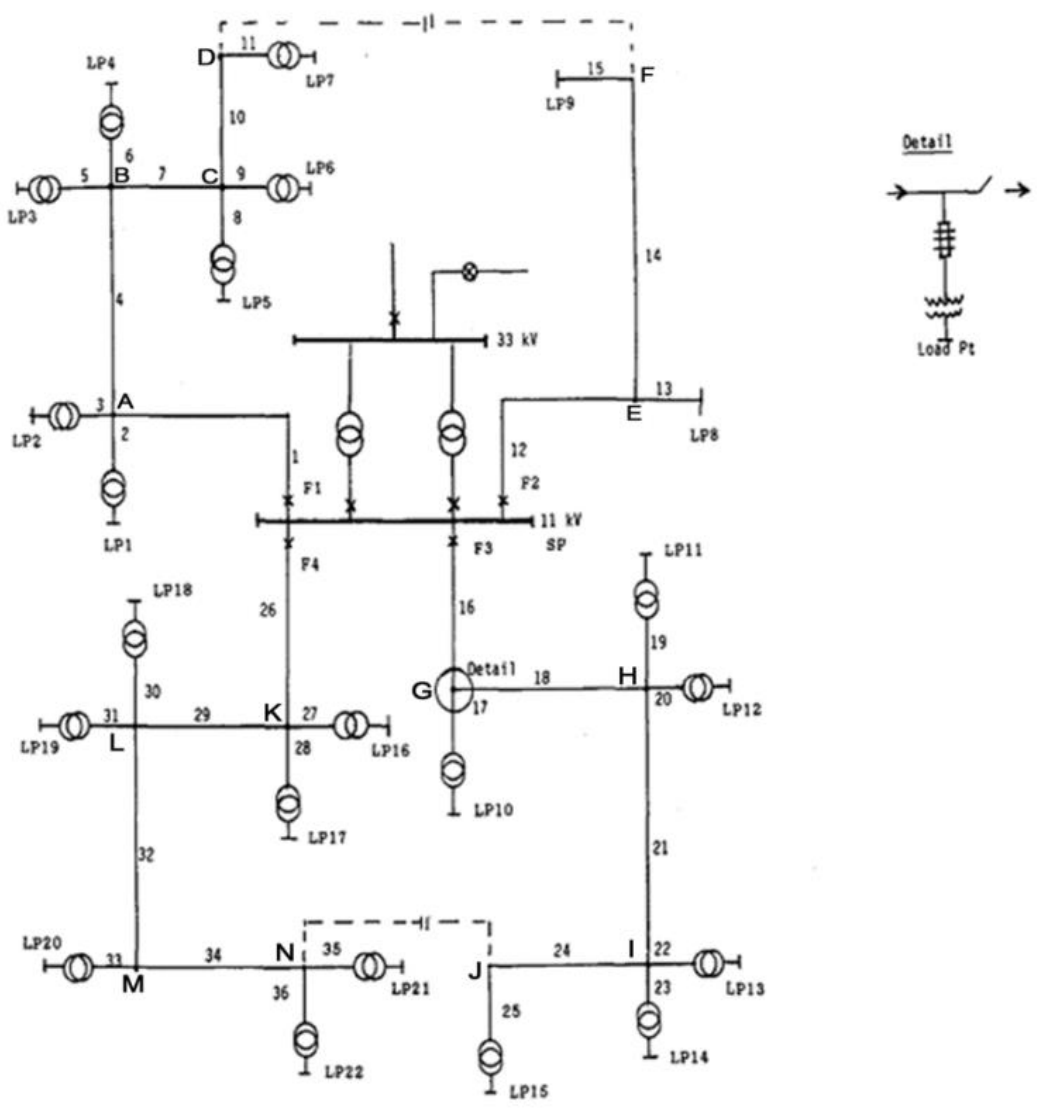

Figure 1. Roy Billinton Test System-Bus 2

\subsection{Analysis and Results}

Initially the system indices are evaluated without any DG in the system and it is considered as the base case. The failure rates and the repair rates of the components are taken as mentioned in [11]. The load point indices are evaluated using the equations 1 to 9 . These values are used to evaluate the system indices. The result of the base case is given in Table 1. The effect of DG connected at points $\mathrm{C}, \mathrm{I}$ and $\mathrm{M}$ on system reliability indices are evaluated. Integration of $D G$ in the system results in reduction of failure rate and the outage time for the load points, thus improving the reliability of the system. The DG considered are one $2 \mathrm{MWand}$ two $1 \mathrm{MW}$ generators. These generators are connected in feeder 1,3 and feeder 4 . DG presence is not considered for feeder 2 as the number of customers connected and their load is very small.The reliability indices in the presence of DGs are given in Table 2.

Table 1. Base Case Reliability Indices

\begin{tabular}{cccc}
\hline Feeder & $\begin{array}{c}\text { SAIFI } \\
\text { (interruptions/yr) }\end{array}$ & $\begin{array}{c}\text { SAIDI } \\
\text { (hrs/customer) }\end{array}$ & ENS (MWh/yr) \\
\hline F1 & 0.25 & 4.40 & 16.07 \\
F2 & 0.14 & 0.87 & 1.84 \\
F3 & 0.25 & 4.26 & 13.34 \\
F4 & 0.25 & 4.19 & 14.41 \\
System & 0.25 & 4.28 & 45.69 \\
\hline
\end{tabular}


Table 2. Reliability Indices for DGs Connected at C, I and M

\begin{tabular}{cccc}
\hline Feeder & $\begin{array}{c}\text { SAIFI } \\
\text { (interruptions/yr) }\end{array}$ & $\begin{array}{c}\text { SAIDI } \\
\text { (hrs/customer) }\end{array}$ & ENS (MWh/yr) \\
\hline F1 & 0.22 & 4.19 & 15.34 \\
F2 & 0.14 & 0.86 & 1.84 \\
F3 & 0.23 & 4.09 & 12.80 \\
F4 & 0.23 & 4.04 & 13.97 \\
System & 0.23 & 4.11 & 43.96 \\
\hline
\end{tabular}

The availability of number of DGs is also considered for the evaluation of reliability indices and the variation of system reliability indices for different number of DGs and their location in the system is given in Table 3.

Table 3.System Reliability Indices for Different Number of DGs

\begin{tabular}{lcccc}
\hline \multicolumn{1}{c}{ No. of DGs } & $\begin{array}{c}\text { SAIFI } \\
\text { (Interruptions/yr) }\end{array}$ & $\begin{array}{c}\text { SAIDI } \\
\text { (hrs/customer) }\end{array}$ & $\begin{array}{c}\text { ENS } \\
\text { (MWh/yr) }\end{array}$ & $\begin{array}{c}\text { \% Reduction in ENS } \\
\text { from base case }\end{array}$ \\
\hline 3 DGs (F1,F3,F4 ) & 0.22 & 4.11 & 43.96 & 4.00 \\
2 DGs (F1,F3) & 0.21 & 3.83 & 40.60 & 11.14 \\
2 DGs (F1,F4) & 0.21 & 3.82 & 41.00 & 10.26 \\
2 DGs (F3,F4) & 0.23 & 4.18 & 44.69 & 2.20 \\
1 DG (F1) & 0.24 & 4.21 & 44.93 & 1.66 \\
1 DG (F3) & 0.24 & 4.22 & 45.13 & 1.22 \\
1 DG (F4) & 0.24 & 4.23 & 45.23 & 1.00 \\
\hline
\end{tabular}

\section{Cost Analysis}

From the above analysis it can be seen that DG integration can improve the reliability of the system. The cost of the DGs is significant and this should be considered for evaluating the benefits. DGs are capable of i) reducing the cost of line loss ii) delaying the requirements of increase in generation and transmission capacities iii) reducing the cost of new feeders and laterals and iv) reducing the fixed charges related to maximum demand of the customer. In addition to these advantages the power generated by DG under normal conditions can be exported to the grid for generating revenue. In this paper the cost benefit analysis and payback period the percentage reduction in ENS and the units that can be given to grid under normal conditions are considered. The connected DG is assumed to be a PV source without any battery backup. Therefore DG produces the power only for a period of $12 \mathrm{hr}$. The individual consumer bills have the mainly three major components namely fixed charges, units consumed and other charges. The fixed charges are based on the maximum demand of the consumer. The rate of tariff depends on the number of units consumed. Other charges include fuel surcharge, electricity tax etc depending on the service providers policy.

In this work individual feeder is considered as single unit for cost evaluation process. The fixed charges depend on the connected load and this component of energy charges will remain the same as the DG type considered is a PV source without any backup. There will be variations in the units consumed from the utility. The steps involved in the evaluation procedure are as follows.

Step 1 : Let the average consumption of power be $\mathrm{X} \mathrm{kW}$. The energy consumption for a period of one year will be $E_{b=} X \times 8760 \mathrm{kWh}$.

Step 2 : If the unit price is taken as $k$, then the total cost of power consumed is $T_{E C}=k \times E_{b}$

Step 3 : After the installation of DG the load on the utility is determined by the size and the availability duration of DG. The energy consumed from the utility during one year will be $\mathrm{E}_{\mathrm{a}=}[(\mathrm{X}-\mathrm{P}) \times 8760+\mathrm{P} \times 8760 / 2] \mathrm{kWh}$

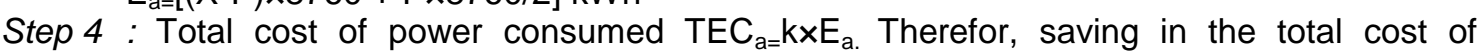
power $=\mathrm{TEC}_{\mathrm{b}}-\mathrm{TEC}_{\mathrm{a}}$.

where, $k$ is the tariff for the units consumed, $P$ is the capacity of the DG unit, $E_{b}$ is the energy consumption from the utility before the $D G$ integration, $E_{a}$ is the energy consumption from the utility after the DG integration, $T_{E C}$ is the total energy cost before $D G$ installation and $T C_{a}$ is the total energy cost after DG installation. 
In addition to the reduction in total energy cost, the integration of DG reduces the losses in the line, this power aids the supply power and utilities can generate revenue. Revenue generated from the reduction in loss is taken as $R G L$ and is given by: $R G L=R s . P_{L}{ }^{*} 8760 * k / y r$, where $P_{L}$ is the reduction in loss. Installation of $D G$ also results in the reduction of ENS index, thus utilities can have an addition revenue.As the DG is generally installed by the consumers $R G L$ and the benefit from ENS reduction is not considered for the benefit evaluation.

From the reliability evaluation it can be observed that significant improvement in reliability is obtained with the installation of DGs in feeder 1 and feeder 3 . The considered DG sizes are $2 \mathrm{MW}$ at and a $1 \mathrm{MW}$ respectively. The cost benefit analysis is carried out for these feeders. The total capital cost requirements of a $2 \mathrm{MW}$ and a $1 \mathrm{MW}$ generator are approximately Rs. 15 Crores. The payback period can be calculated as hown below.

The average load of feeder 1 is $3630 \mathrm{~kW}$

The units consumed in one year $\mathrm{E}_{\mathrm{b}}=3630 * 8760 \mathrm{kWh}$

The unit price is assumed to be Rs. 9.70 [12]

The $T_{E C}$ is=Rs. 30.85 Crore

After DG integration, units consumed in one year $E_{a}=(3630-2000) \times 8760+2000 \times 8760 / 2$

Thus, the TEC $_{a=}$ Rs. 22.35 crore

The saving in TEC is: TEC $_{b}-$ TEC $_{b}=R s .8 .5$ crore per year

Similar calculation is carried out on feeder 3 and TEC for feeder 3 is Rs. 4.24 crores.

The total savings account to be Rs. 12.74 crores.

Therefore the payback period $=($ Total investment $) /($ Total savings $)=$

Payback period for this case is obtained as 1 year 2 months. In this analysis only the capital cost of the DGs are considered and their installation \& maintenance costs of DG are not considered. If these charges and the DG output variations are taken into account for the evaluation of payback period, it will be less than three years. Table 4 shows the payback period for different DG penetration levels for feeder 1 and feeder 3. At each level of penetration commercially available syandard DG sizes are considered.

Table 4. Variation in Annual Savings

\begin{tabular}{cccc}
\hline DG penetration & $\begin{array}{c}\text { TEC }_{b} \\
\text { Rs.(Crore) }\end{array}$ & $\begin{array}{c}\text { TEC } \\
\text { Rs.(Crore) }\end{array}$ & $\begin{array}{c}\text { Annual saving } \\
\text { Rs.(Crore) }\end{array}$ \\
\hline 20\%-F1 & 30.85 & 22.34 & 8.45 \\
20\%-F3 & 26.39 & 22.14 & 4.25 \\
30\%-F1 & 30.85 & 22.34 & 7.55 \\
30\%-F3 & 26.39 & 22.14 & 7.01 \\
40\%-F1 & 30.85 & 20.05 & 10.07 \\
40\%-F3 & 26.39 & 17.89 & 8.49 \\
\hline
\end{tabular}

\section{Conclusion}

DGs provide an alternate solution for improving the reliability of the system. In this paper, the effect of the location and number of DGs on the system reliability is studied. The variation in the system reliability is evaluated when multiple DGs are integrated into the system. It is observed that there is a significant improvement in the reliability when DGs are placed in feeder 1 and feeder 3 and this case is considered for the evaluation of payback period. It is pragmatic that as the size of the DG is increases, the cost of the DG increases but this helps in reducing the units consumed from the grid. Thus the annual savings will increase with the increase in DG size. This analysis helps in the process of decision making in choosing the size of DG.

\section{References}

[1] Guldbrand, Anna. Reliability Engineering Methods for Distribution Systems-Influence of Differences between Cable Systems and Overhead Lines. TEIE. 2007.

[2] Bertling, Lina, Roland Eriksson, RN Allan. Impact of maintenance strategy on cost and reliability of distribution system. In Proceedings of CIRED. 2003.

[3] Hilber, Patrik. Maintenance optimization for power distribution systems. Doctoral thesis Royal Institute of Technology, Stockholm, Sweden. 2008 
[4] Cho, Sung-Min, Hee-Sang Shin, Jin-Hyun Park, Jae-Chul Kim. Distribution system reconfiguration considering customer and DG reliability cost. Journal of Electrical Engineering and Technology 7. 2012; (4): 486-492.

[5] Zhu, Dan. Electric Distribution Reliability Analysis Considering Time-varying Load, Weather Conditions and Reconfiguration with Distributed Generation. 2007.

[6] Heidari, Alireza, Vassilios Georgios Agelidis, Mohammad Salay Naderi. Effects of automation on the reliability of power distribution systems considering distributed generation: Worth analysis. In Industrial Technology (ICIT). IEEE International Conference. 2013: 1733-1738.

[7] Sagar, E Vidya, PVN Prasad. Reliability Improvement of Radial Distribution System with Smart Grid Technology. In Proceedings of the World Congress on Engineering and Computer Science. $2013 ; 1$.

[8] Javadian, Seyed Ali Mohammad Maryam Massaeli. Impact of Distributed Generation on Distribution Systems Reliability considering Recloser-fuse Miscoordination-a Practical Case Study. Indian Journal of Science and Technology 4. 2011; (10): 1279-1284.

[9] Yuan, Yue, Kejun Qian, Chengke Zhou. The effect of Distributed Generation on distribution system reliability. In Universities Power Engineering Conference, UPEC, 42nd International, IEEE. 2007: 911-916.

[10] Ngaopitakkul, Atthapol, Chaichan Pothisarn, Sulee Bunjongjit, Boonlert Suechoey, Chaiyo Thammart, Auttarat Nawikavatan. A reliability impact and assessment of distributed generation integration to distribution system. Energy and Power Engineering 5. 2013: (04): 1043.

[11] Allan, Ronald N, Ro+y Billinton, I Sjarief, L Goel, and KS So. A reliability test system for educational purposes-basic distribution system data and results. Power Systems, IEEE Transactions on 6. 1991: (2): 813-820.

[12] https: Itssouthernpower.com 